\title{
Aislación y Caracterización de Células Madre Mesenquimales Provenientes de Pulpa y Folículo Dentario Humano
}

\author{
Isolation and Characterization of Mesenchymal Stem Cells \\ from Human Dental Pulp and Follicle
}

\author{
Claudia Brizuela C.*; Sussy Galleguillos G.**; Flavio Carrión A.***; \\ Carolina Cabrera P.****; Patricia Luz C.***** \& Carolina Inostroza S.
}

BRIZUEla C. C.; GAlleguillos, G. S.; CARRIón, A. F.; CABRERA, P. C.; LUZ, C. P. \& INOSTROZA, S. C. Aislación y caracterización de células madre mesenquimales provenientes de pulpa y folículo dentario humano. Int. J. Morphol., 31(2):739-746, 2013.

RESUMEN: Recientemente se ha descubierto que diversos tejidos dentales son fuente importante de Células Madre Mesenquimales (CMM). En la cavidad oral podemos encontrar CMM en la pulpa, en el folículo dental, papila y en la encía entre otros lugares. Varios estudios avalan el extenso potencial terapéutico de las CMM en terapias de regeneración. El objetivo de este estudio es aislar, cultivar células madres mesenquimales de pulpa y folículo dental humano, caracterizar su inmunofenotipo y su potencial de diferenciación a linaje osteogénico, condrogénico y osteogénico. Se cultivaron células de pulpa y folículo dental de terceros molares de dientes permanentes jóvenes humanos. Los cultivos de CMM fueron monitoreados por microscopia óptica, las células se inmunotipificaron por citometría de flujo. Posteriormente se evaluó su capacidad de diferenciaron a los tres linajes mencionados. En estas condiciones experimentales se comprobó que las células aisladas y cultivadas de pulpa y folículo dental correspondían a células madre mesenquimales humanas, siendo éstas últimas más fáciles de obtener y proliferar. Las CMM de folículo dental poseen mayor potencial de crecimiento y capacidad de diferenciación en comparación a las CMM de pulpa dental, probablemente debido a su estado evolutivo más inmaduro.

PALABRAS CLAVE: Células madre mesenquimales; Pulpa y folículo dental; Diferenciación multilinaje; Potencial de proliferación.

\section{INTRODUCCIÓN}

En ingeniería tisular, las células más prometedoras, son las células madres mesenquimales (CMM) adultas. Estas CMM son indiferenciadas con capacidad de autorenovarse, pluripotentes, presentan morfología fibroblastoide y plasticidad hacia diversos linajes celulares como condrocitos, osteocitos y adipocitos entre otros. Estas células pueden ser aisladas principalmente de médula ósea, cordón umbilical y tejido adiposo. Se han hecho proliferar en cultivos in vitro, lo que ha permitido estudiar algunas de sus propiedades funcionales (Friedlander, 2009; Saber, 2009; Petrovic \& Stefanovic, 2009; Yen \& Yelick, 2011). Aunque el tema en torno a su variada utilización todavía mantiene algunas interrogantes, su estudio contempla uno de los campos de la investigación más activos en el ultimo tiempo (Kenneth, 2012; Sunil et al., 2012). Su utilidad radica tanto en su fácil obtención y extenso potencial terapéutico, que poseen gracias a su plasticidad. Esta última característica les permite formar células de linaje diferente a su origen, (Yen \& Yelick, 2011). Han podido ser aisladas, cultivadas y caracterizadas de diversos tejidos, dentro de los cuales se incluyen tejidos bucodentarios (Friedlander, Mitrano et al., 2010, Thomson \& Kahler, 2010, Yen \& Yelick, 2011, Bansal, 2011).

En la última década se han estudiado las células madres, sus nichos y señales específicas que modulan su potencial de diferenciación (Rodríguez-Lozano et al., 2011, Mitsiadis et al., 2011).

Cirujano Dentista. Especialista en Endodoncia. Profesor Asociado de Endodoncia. Facultad de Odontología, Universidad de los Andes. Magister en Educación ( Pontificia Universidad Católica de Chile.

** $\quad$ Cirujano Dentista, Universidad de los Andes, Chile.

*** $\quad$ Profesor Asociado, Bioquímico, Doctor en Ciencias Biológicas, Laboratorio de Inmunología Celular y Molecular. Facultad de Medicina, Universidad de Los Andes.

***** Cirujano Dentista. Especialista en Endodoncia. Docente de Endodoncia. Facultad de Odontología, Universidad de los Andes, Chile.

****** Ingeniero en Biotecnología. Doctor en Biotecnología. Laboratorio de Terapia Celular. Facultad de Medicina. Universidad de los Andes, Chile.

******* Profesor Asistente, Bioquímica. Magíster en Ciencias. Centro de Investigación en Biología y Regeneración Oral (CIBRO), Facultad de Odontología, Universidad de los Andes, Chile.

Financiamiento: Proyecto FIC-ODO 2009, Facultad de Odontología, Universidad de los Andes. Santiago Chile. 
En la cavidad oral podemos encontrarlas en la pulpa, en el folículo dental y en el tejido conectivo gingival entre otros (Chen et al., 2012). La pulpa posee células mesenquimáticas indiferenciadas que derivan del ectodermo de la cresta neural, constituyendo una verdadera reserva celular, poseen capacidad de diferenciarse en nuevos odontoblastos o fibroblastos según el estímulo que actúe sobre ellas (Murray et al., 2008, Yen \& Yelick, 2011, Suzuki et al., 2011).

El folículo dental es un tejido conectivo blando, de origen mesenquimal, que rodea el órgano del esmalte y la papila dental del germen dentario en desarrollo (Rodríguez-Lozano et al.; d'Aquino, 2011). Se forma durante la etapa de copa (odontogénesis), a partir de una población de células progenitoras del ectomesénquima que derivan de las crestas neurales. Corresponde a una fuente rica en células madres mesenquimales que puede persistir durante la vida adulta en caso de dientes impactados (terceros molares) y se suele extraer en conjunto con éstas y ser descartado como desecho biológico en la atención dental (Honda et al., 2010; d'Aquino; Angiero et al., 2012). Algunos de los usos de estas células han sido para desarrollar modelos de regeneración de tejido periodontal in vivo. Por ejemplo Guo et al. (2012), demostró en su estudio que incluso en pasaje 30 estas células podían ser utilizadas mezcladas con hueso bovino cerámico en modelo animal.

Existen criterios mínimos para definir células madres mesenquimales humanas, tanto para investigaciones científicas basadas en experimentación in vitro, como para estudios pre-clínicos según The International Society for Cellular Therapy position statement (Dominici et al., 2006, Flores et al., 2006, Salinas \& Anseth, 2009; RodríguezLozano et al.). Dentro de estos criterios podemos mencionar:

a) Adherencia al plástico en condiciones estándar de cultivo. b) Morfología celular fibroblastoide. c) Expresión de antígenos (marcadores) de superficie específicos, que comprende que más de un $95 \%$ de la población celular exprese fenotipo positivo para CD73, CD90 y CD105 y menos de un 3\% de la población exprese fenotipo negativo para CD34 (marcador de célula endotelial), CD45 (leucocitario), CD14 y CD11 (marcadores de macrófagos y monocitos), CD79 y CD19 (marcadores de células B) y HLA-DR (clase II). d) Capacidad multipotencial de diferenciación hacia linaje osteogénico, condrogénico y osteogénico, bajo condiciones in vitro estándar y demostradas con tinción específica.

La diferenciación es un proceso en donde las célu- las indiferenciadas se especializan hacia subtipos específicos. Está gatillado por señales tanto intracelulares como extracelulares (Howard et al., 2008; Saber).

El objetivo de este estudio es aislar, cultivar células madres mesenquimales de pulpa y folículo dental humano, caracterizar su inmunofenotipo y su potencial de diferenciación a linaje osteogénico, condrogénico y adipogénico.

\section{MATERIAL Y MÉTODO}

Purificación y cultivo de CMM adultas. En el Centro de Salud de la Facultad de Odontología de la Universidad de los Andes se recolectaron terceros molares impactados sin caries de pacientes jóvenes sanos sistémicamente, hombre o mujer (16-18 años de edad). Para la extracción, el rostro del paciente fue desinfectado con una solución de clorhexidina al $0,2 \%$ y fue anestesiado con anestesia local (Clorhidrato de lidocaína, Levoarterenolbitartrato) al $2 \%$. Los dientes extraídos fueron limpiados con una solución de suero fisiológico y posteriormente transportadas al Laboratorio (CIBRO). La obtención y la manipulación de las muestras humanas se realizó bajo las consideraciones exigidas por el Comité de Bioética de la Universidad de los Andes.

En los dientes impactados podemos encontrar dos tejidos, pulpa y folículo dental, los cuales fueron extraídos a través del ápice con un extractor pulpar. Cada tejido fue cuidadosamente extraido del diente y disgregado mediante la utilización de hoja bisturí $\mathrm{N}^{\circ} 15$. Los explantes fueron cultivados en placas de cultivo con un medio completo compuesto por a-MEM (Minimal Eagle Medium, Invitrogen), 20\% de suero fetal bovino (SFB), (HyClone, ) y $1 \%$ de Antibiótico (Penicilina-Estreptomicina, PenStrep, Invitrogen). A los 10 días se realizó el cambio de medio y el explante fue eliminado.

A las 4 semanas de seguimiento de los cultivos de tejido pulpar y de folículo dental, se observaron las primeras células con fenotipo fibroblastoide adheridas al plástico. Obtenidas las células, se resuspendieron en $3 \mathrm{ml}$ de medio completo, se contaron en una cámara de Neubauer (Neubauer Improved Pright Line, 0,1 $\mathrm{mm}$ de profundidad, $0,0025 \mathrm{~mm}^{2}, \mathrm{HBG}$ ) y se sembraron en flask de $25 \mathrm{ml}$ a una concentración de 10.000 cels $/ \mathrm{cm}^{2}$.

Se cultivaron durante 3 semanas hasta alcanzar la confluencia cercana al $80 \%$ y se tripsinizaron con $1 \mathrm{ml}$ de Tripsina (TrypeSelect, Invitrogen) durante 5 minutos a 
$37^{\circ} \mathrm{C}$, para posteriormente, lavar en solución fosfatada tamponada PBS 1x (Hyclone) y centrifugar a $1.680 \mathrm{rpm}$ por 5 minutos a temperatura ambiente. De este modo las CMM entran al pasaje 1 . Se cultivaron hasta el pasaje 4 para la caracterización celular y realización de los ensayos funcionales.

Caracterización de CMM derivadas de tejido pulpar y folículo dental. Para la caracterización in vitro se consideraron los criterios publicados según (Friedstein et al., 1987, Dominici et al.): adherencia al plástico, morfología fibroblastoide y diferenciación a linaje condrogénico, osteoclastogénico y adipogénico (Tokalov et al., 2007). Las diferenciaciones a multilinaje se realizaron según protocolos descritos en el Technical Manual, Stem Cell Technologies (2008), versión 1.2.0.

Inmunofenotipo de CMM. La inmunotipificacion de las CMM en pasaje 4 fue realizada mediante citometría de flujo utilizando anticuerpos conjugados con fluoresceinisothiocyanate-(FITC), phycoerytrin-(PE) o peridinin chlorophyllprotein (PerCP): anti-CD34 (Beckmann Coulter), anti-CD45 (Beckmann Coulter), anti-CD73 (BDPharmingen), anti-CD90 (BDPharmingen) y anti-CD105 (Caltag). La adquisición y análisis de las muestras fue realizada utilizando un citómetro de flujo marca Coulter Epics-XL (Coulter Corporation, Florida, USA).

Ensayos de Diferenciación. Las CMM en pasaje 4 y con una confluencia del $80 \%$ fueron sembradas en 3 placas diferentes, para la inducción hacia la diferenciación adipogénica, osteogénica y condrogénica y CMM sin medios de inducción. Durante la diferenciación se realizaron cambios de medio fresco de inducción cada 4 días. La duración del proceso varió según el linaje celular. Se realizaron tinciones específicas indicadoras de la diferenciación y se registraron fotos en microscopio óptico de luz invertido con contraste de fase Olympus CKX41.

a. Diferenciación Osteogénica: Se sembraron células en una densidad de $35.000 \mathrm{cel} / \mathrm{cm}^{2}$ en placas de 4 pocillos. Se incubaron en la estufa a $37^{\circ} \mathrm{C}$ con $5 \% \mathrm{CO}_{2}$ toda la noche. Al día siguiente, se observaron las células al microscopio óptico. Al alcanzar el $100 \%$ de confluencia, se agregaron $500 \mu \mathrm{l}$ de medio de diferenciación con alfa-MEM, SFB $10 \%$, Penicilina y Estreptomicina (1\%), dexametasona $(0,1 \mathrm{mM})$, B-Glicerofosfato $(10 \mathrm{mM})$, ascorbato-2 fosfato $(50 \mathrm{mg} / \mathrm{ml})$. Este último se agregó día por medio durante todo el proceso de diferenciación. Se mantuvieron incubadas en estufa a $37^{\circ} \mathrm{C}$ con $5 \%$ de $\mathrm{CO}_{2}$ durante todo el proceso. Cuando se observaron cúmulos de minerales y cristales birrefringentes al microscopio (al cabo de 4 semanas), se detuvo la diferenciación y las células se tiñeron con solución Alizarin Red $40 \mathrm{mM}$ en $\mathrm{NaH}_{2} \mathrm{PO}_{4} 0,1 \mathrm{M} \mathrm{pH}$ 4,3 (Sigma). Las células en las placas fueron lavadas 2 veces con $0,25 \mathrm{ml} / \mathrm{cm}^{2}$ de PBS $1 \mathrm{x}$ y fijadas con $0,25 \mathrm{ml} / \mathrm{cm}^{2}$ de etanol $70 \%(\mathrm{v} / \mathrm{v})$ por 30 minutos a temperatura ambiente. Luego las células fueron lavadas 2 veces con PBS 1x, agregándoseles $0,25 \mathrm{ml} / \mathrm{cm}^{2}$ de Alizarin Red $40 \mathrm{mM}$ por 10 minutos a temperatura ambiente. Las células fueron nuevamente lavadas 2 veces con PBS 1x y finalmente se lavaron 5 veces con agua bidestilada.

b. Diferenciación Condrogénica: Se sembraron células en una densidad de $30.000 \mathrm{cel} / \mathrm{cm}^{2}$ en forma de microgota en placas de 4 pocillos, para lograr la formación de micromasa, se incubaron por una hora y media para luego agregarles el medio de diferenciación específico con alfaMEM, SFB 10\%, Penicilina y Estreptomicina (1\%), Dexametasona $(0,1 \mathrm{mM})$, Insulina $(5 \mathrm{mg} / \mathrm{ml})$, TGF- Beta $1(10 \mathrm{ng} / \mathrm{ml})$, ascorbato-2-fosfato $(50 \mathrm{mg} / \mathrm{ml})$. Estos dos últimos se agregaron día por medio durante todo el proceso de diferenciación. A las 2 semanas se verificaron micromasas celulares y se detuvo la diferenciación. Estas fueron teñidas mediante Safranina O, preparando una solución de safranina $\mathrm{O}$ al 0,1\% p/v. Las células fueron lavadas 1 vez con PBS $1 \mathrm{x}$ y luego fijadas con $0,15 \mathrm{ml} / \mathrm{cm}^{2}$ de etanol al $70 \% \mathrm{v} / \mathrm{v}$ por 10 minutos. Se lavaron con PBS 1x para luego agregar $0,15 \mathrm{ml} / \mathrm{cm}^{2}$ de safranina por $5 \mathrm{mi}-$ nutos a temperatura ambiente. Posteriormente fueron lavadas 5 veces con $0,15 \mathrm{ml} / \mathrm{cm}^{2}$ de etanol absoluto (100\%) y por 5 veces con agua bidestilada.

c. Diferenciación Adipogénica: Se sembraron células en una densidad de $25.000 \mathrm{cel} / \mathrm{cm}^{2}$ en placas de 4 pocillos. Se incubaron en la estufa a $37^{\circ} \mathrm{C}$ con $5 \% \mathrm{CO}_{2}$ durante un día. Al día siguiente, se observaron las células al microscopio óptico. Al alcanzar el 100\% de confluencia, se agregó $500 \mu \mathrm{l}$ de medio de diferenciación con: (alfa-MEM, SFB $10 \%$, Penicilina y Estreptomicina (1\%), Dexametasona $(0,11 \mathrm{mM})$, Insulina $(10 \mathrm{mg} / \mathrm{ml})$, Indometacina $(0,02 \mathrm{mg} / \mathrm{ml})$. A las 4 semanas las CMM fueron lavadas con PBS 1x y se marcaron con una solución saturada de Oil Red en isopropanol $60 \%$ v/v por 1 hora a temperatura ambiente. Las CMM se lavaron 2 veces con PBS 1x.

\section{RESULTADOS}

Cultivo Celular. Una vez iniciado el cultivo del explante, las células fueron observadas diariamente bajo microscopía óptica para evaluar morfología fibroblastoide y adherencia a la superficie plástica, según los criterios 


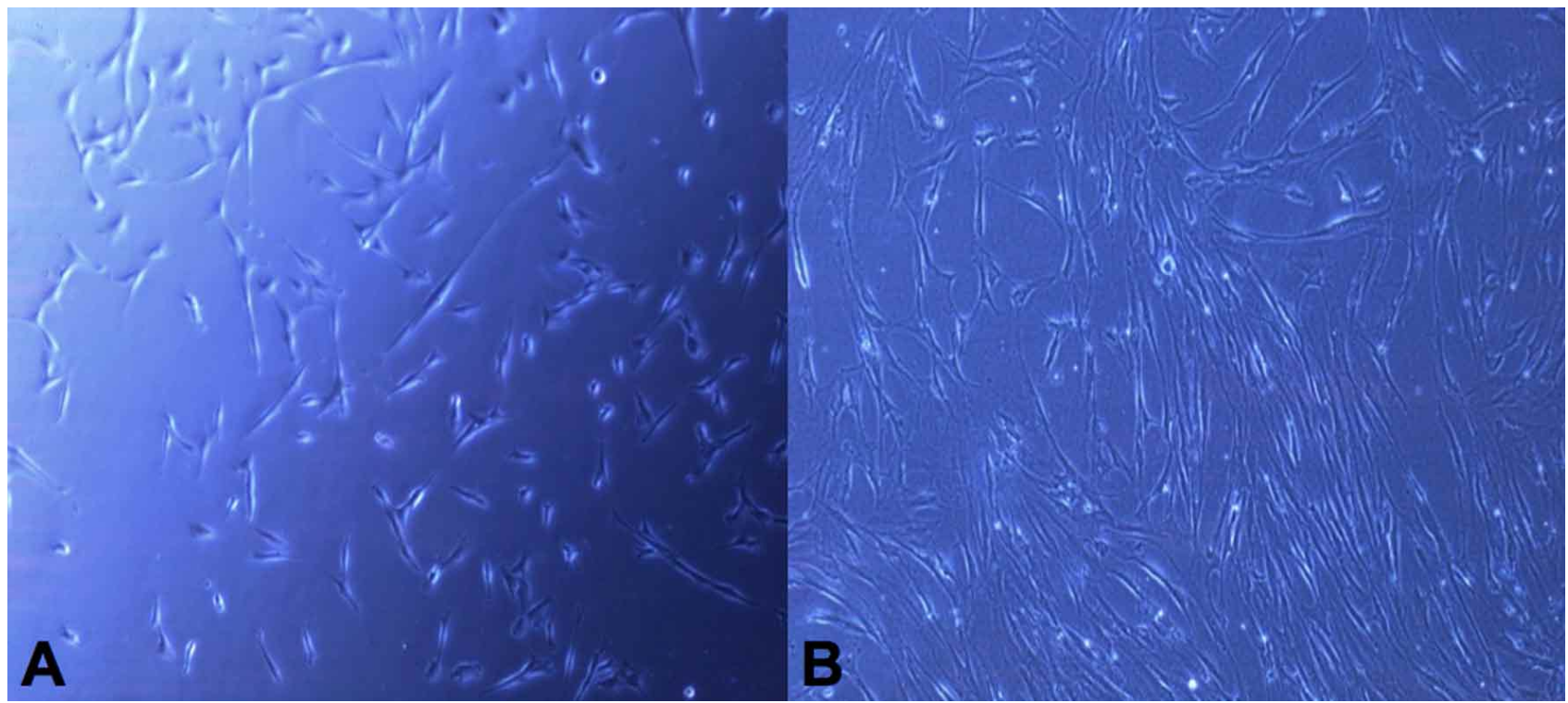

Fig. 1. Cultivo celular. A: Células de pulpa dental, luego de 4 semanas de cultivo alcanzaron un 20\% de confluencia. B. Células de folículo dental con una confluencia del $60 \%$. Microscopía óptica, magnificación 20X.

de la ISCT (Dominici et al.,). A las 4 semanas de cultivo se observó la presencia de células madres mesenquimales con la morfología mencionada y adherencia al plástico. Las CMM de pulpa dental alcanzaron una confluencia de un $20 \%$ y las CMM de folículo dental un $60 \%$. Se demuestra su capacidad de proliferación en las figuras $1 \mathrm{~A}$ y $1 \mathrm{~B}$, respectivamente. En la figura 2 se observaron los cultivos de CMM derivadas de la pulpa y folículo dental que alcanzaron una confluencia del $100 \%$.

Caracterización Inmunofenotípica. Las CMM derivadas de pulpa dental y folículo fueron analizadas median- te citometría de flujo, demostrando aproximadamente un 99\% de expresión positiva para los marcadores CD73, CD90, CD44 y CD105 y menos de un 3\% de expresión para los marcadores CD34, CD54, CD38 y CD45, respectivamente. Figs. 3A y 3B respectivamente.

Ensayos de Diferenciación. Los ensayos de diferenciación muestran que las CMM de pulpa fueron capaces de diferenciarse a linaje osteogénico, condrogénico (Figs. 4A, 4B y 4C) y las CMM de folículo dental hacia linaje osteogénico, condrogénico y adipogénico (Figs. 5A, 5B y $5 \mathrm{C}$ ).

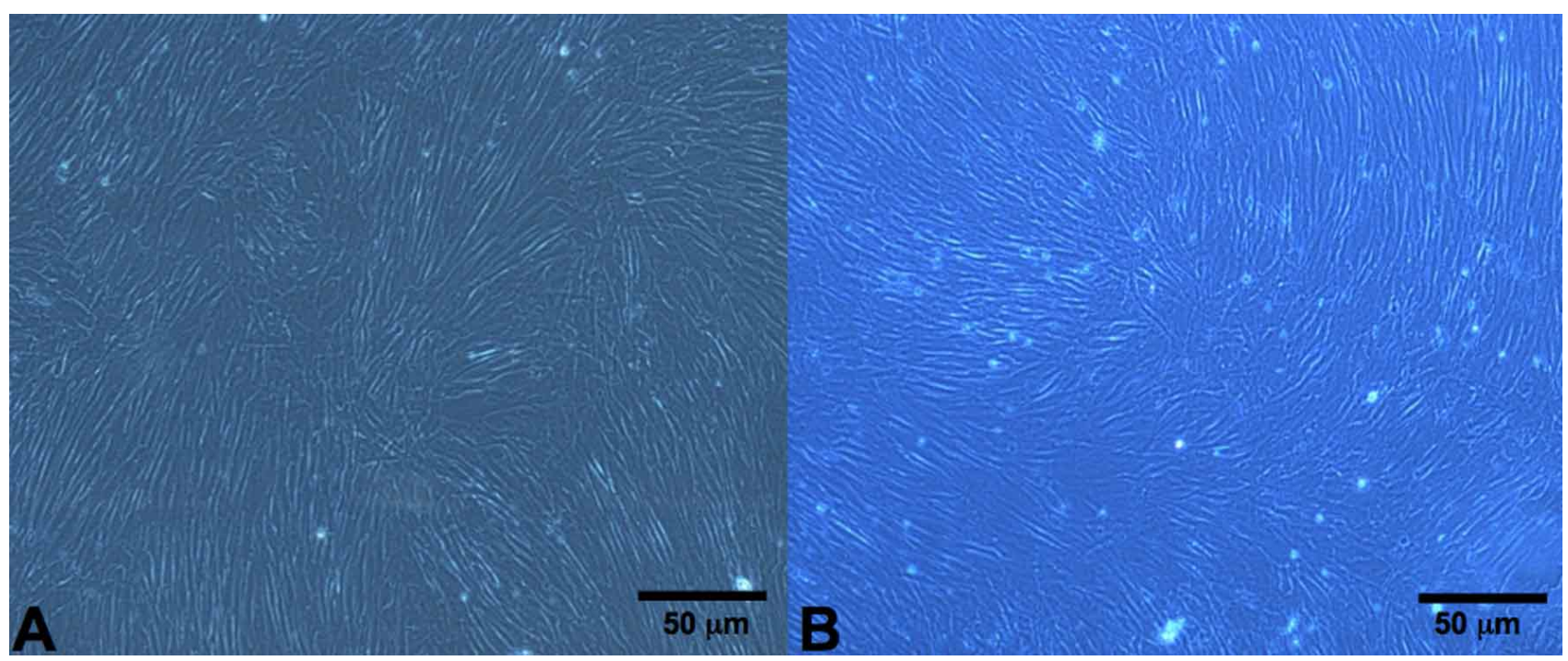

Fig. 2. Proliferación celular. A . CMM de la pulpa dental. B. CMM de folículo dental. Ambos cultivos de CMM en pasaje 4, alcanzando un $100 \%$ de confluencia. Microscopia óptica, magnificación 10X. 

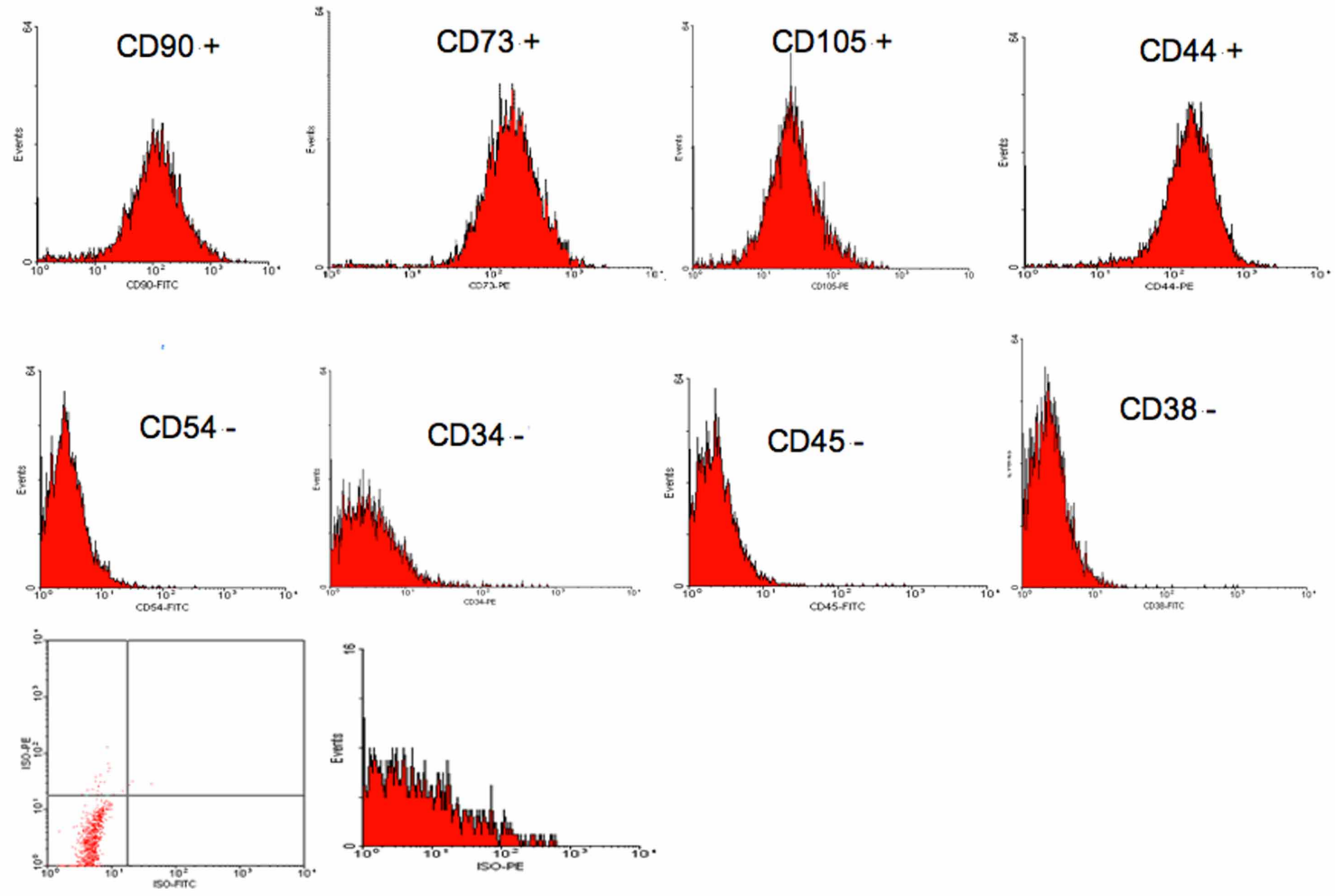

A. Histograma de citometría para CMM de origen pulpar.
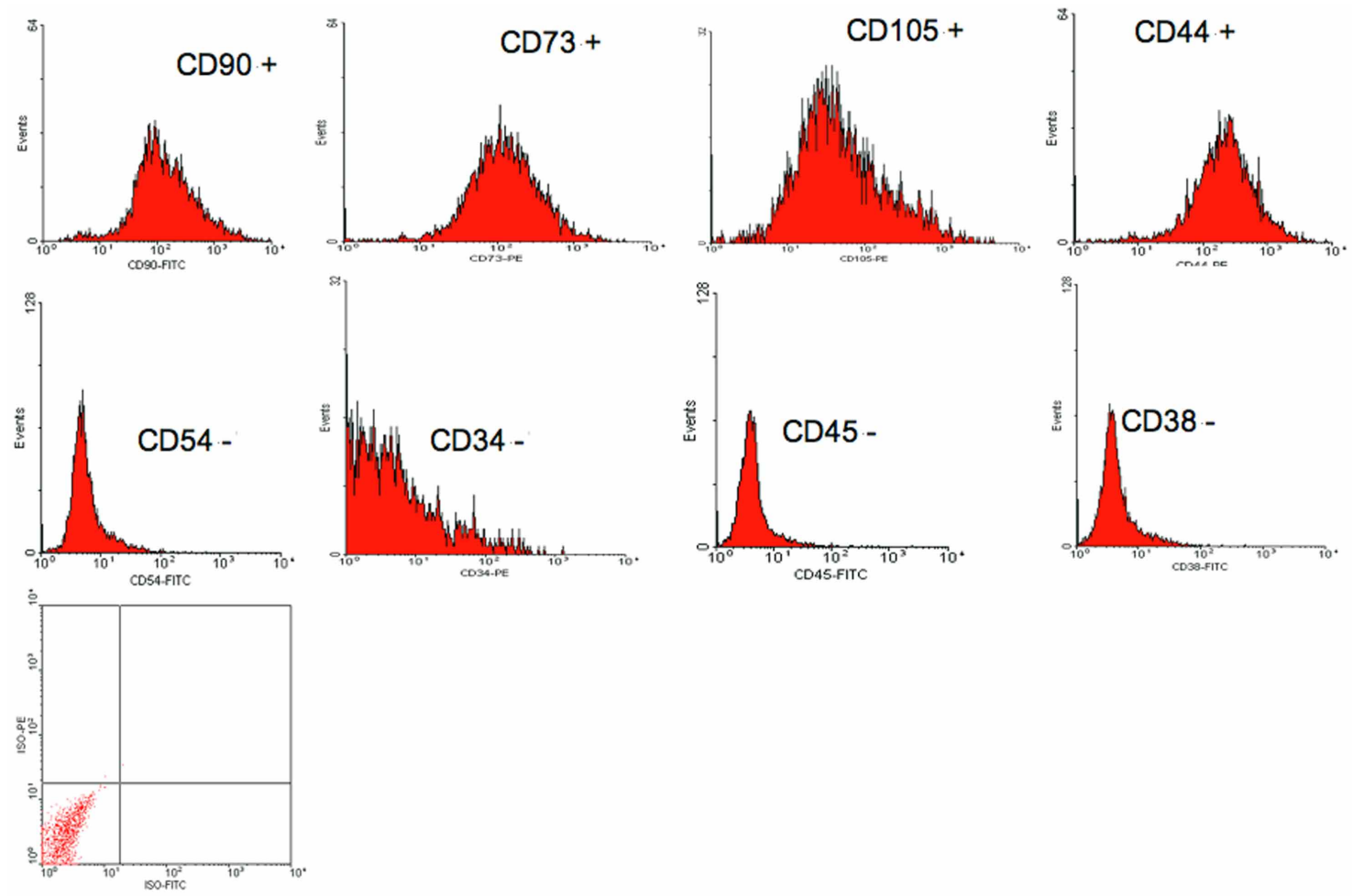

B. Histograma de citometría para CMM de folículo dental.

Fig. 3. Caracterización inmunofenotípica. 


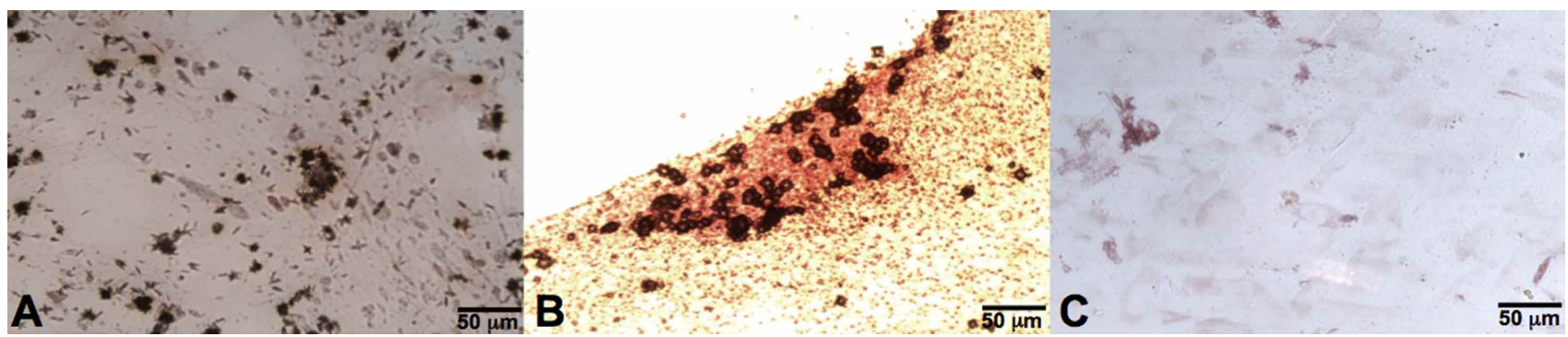

Fig. 4. Diferenciacion celular de CMM de origen pulpar. A: Diferenciación osteogénica, tejido teñido de rojo oscuro con Alizarin Red. B: Diferenciación condrogénica, micromasa teñida de rojo con Safranina O. C: Diferenciación adipogénica, adipocitos teñidos de rojo con Oil Red. Microscopía con contraste de fase.

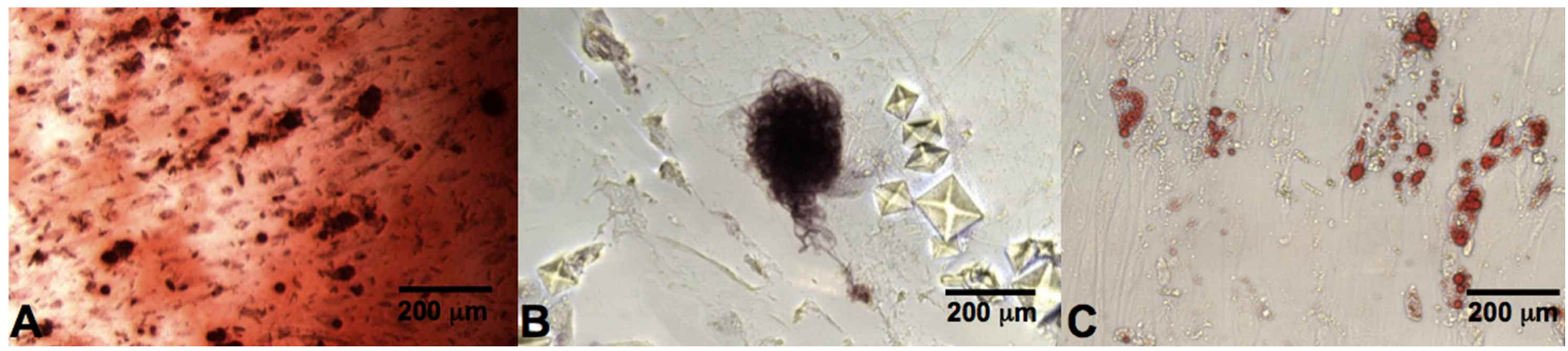

Fig. 5. Diferenciación celular de CMM de folículo dental. A. Diferenciación osteogénica, tejido teñido de rojo oscuro con Alizarin Red. B. Diferenciación condrogénica, micromasa teñida de rojo con Safranina O. C. Diferenciación adipogénica,adipocitos teñidos de rojo con Oil Red. Microscopía con contraste de fase.

\section{DISCUSIÓN}

Las células madres constituyen una fuente celular útil en la generación de tejidos durante el desarrollo y además, para la regeneración de los tejidos que están lesionados o enfermos después del nacimiento. En los últimos años, la investigación con células madres ha crecido de manera exponencial, debido al reconocimiento de terapias basadas en células madres, que mejoran la vida de los pacientes con condiciones que abarcan desde enfermedad de Alzheimer, isquemia cardiaca, pérdida de hueso o dientes (Casagrande et al., 2011). La biología de las células madre es un campo importante para comprender la regeneración tisular (Huang, 2008; Huang et al., 2008). La utilidad de las células madre mesenquimales en aplicaciones clínicas depende de la accesibilidad al tejido de origen, tasa de proliferación y de su potencial de diferenciación (Casagrande et al.). El objetivo de este estudio fue aislar, cultivar células madres mesenquimales de pulpa y folículo dental humano y caracterizar su inmunofenotipo y su potencial de diferenciación a linaje osteogénico, condrogénico y adipogénico. Para lograr este objetivo, se definió el tipo de diente a utilizar, que en este caso fueron terceros molares de pacientes jóvenes entre 16 y 18 años de edad. Para determinar la existencia de CMM derivadas del folículo y pulpa dental humana se llevó a cabo el cultivo de sus células a partir de un explante.
Las colonias celulares derivadas del folículo dental presentaron una mayor confluencia de aparición en comparación a las pulpares. Sin embargo, esto se puede deber a la composición diferente que presentan los tejidos. Mientras que el folículo corresponde a un tejido conectivo de características laxas, la pulpa presenta un tejido conectivo de características más fibrosas. Interesantemente, cuando ambos cultivos se realizaban bajos las mismas condiciones de tiempo, espacio, y medio de inducción, las CMM de folículo dental presentaron un mayor potencial de diferenciación en comparación a las CMM de pulpa in vitro. Esto tal vez se puede atribuir al estado de desarrollo de los distintos tejidos, el folículo dental estaría en un estado de desarrollo embrionario en comparación al tejido pulpar. Es necesario destacar que en las condiciones de este experimento, las CMM de folículo dental lograron diferenciarse hacia adipocitos, mientras que las CMM de pulpa no lograron tener esa capacidad, indicando así el mayor potencial de diferenciación que presentan las células de folículo dental en comparación a las de pulpa.

Nuestra investigación también demostró el potencial de CMM de pulpa y folículo dental de formar depósitos calcificados in vitro. A pesar de que las CMM pulpares hayan formado nódulos calcificados y fallado en su capacidad 
adipogénica, las CMM de folículo dental presentaron un gran potencial de diferenciación hacia condrocitos, osteocitos y adipocitos.

Estudios anteriores han observado el potencial odontogénico de las CMM de pulpa y de folículo dental utilizando diferentes métodos de cultivo (Buurma et al., 1999; Yao et al., 2008). Durante el desarrollo dentario, la interacción que ocurre entre las células epiteliales de la porción interna del órgano del esmalte y las células mesenquimales de la papila dental, da lugar a la diferenciación de ameloblastos y odontoblastos. Una vez formadas estas células, los tejidos que sintetizan no se logran renovar como lo hace el hueso, el cual lentamente se remodela durante la vida. Sin embargo, luego de la erupción dentaria, el daño que sufre la dentina debido a factores químicos, físicos y mecánicos, induce la formación de dentina reparativa, la cual se caracteriza por presentar una matriz dentinaria pobremente organizada, que permite la protección del órgano pulpar. Se ha pensado que las células se obtienen de la pulpa, y son ellas las que generan este tejido ya que finalmente se terminan diferenciando a odontoblastos (Smith et al., 1995). El folículo dental se diferencia hacia ligamento periodontal, debido a esto, podría ser el precursor de otros tipos celulares del periodonto, incluyendo osteoblastos y cementoblastos (Yao et al.). Algunos estudios indican que cierta parte de la población celular del folículo dental se diferencia hacia cementoblasto. Sin embargo, no existe la certeza que estos cementoblastos provienen de las CMM del folículo dental (Yao et al.)
Aunque ambos tejidos se ubican en distintas zonas anatómicas de la cavidad oral, las CMM de ambos comparten ciertas características; presentaron marcaje o inmunotipificación positiva frente a anticuerpos CD44, CD105, CD73 y CD90 y negativo para CD34, CD45, CD54, además, demostraron adherencia al plástico, capacidad proliferativa en el tiempo y se diferenciaron hacia condrocitos y osteocitos frente a los mismos medios de diferenciación. Estos hallazgos son similares a los encontrados por otros autores, que muestran que las células madres comparten un perfil de expresión similar de marcadores celulares, como el Stro-1, SH2 (CD105), SH4 (CD73), CD90, CD146 y CD29 y comúnmente carecen de marcadores celulares hematopoyéticos como el CD34 y CD45 (Zhang et al., 2009).

La información de esta investigación demuestra que las CMM de pulpa y folículo dental presentan una gran capacidad proliferativa, poseen plasticidad, existen indiferenciadas y mantienen este fenotipo hasta que son expuestas a señales apropiadas, tienen la habilidad de autorenovarse por tiempos prolongados de tiempo (pasajes). En consecuencia, existe un gran potencial para aislar CMM de pulpa y folículo dental de un sólo diente que pudieran ser utilizadas en medicina y odontología regenerativa.

AGRADECIMIENTOS: Agradecemos a la Facultad de Odontología de la Universidad de los Andes por el apoyo y financiamiento otorgado.

BRIZUela C. C.; GAlleguillos, G. S.; CARRIÓN, A. F.; CABRERA, P. C.; LUZ, C. P. \& INOSTROZA, S. C. Isolation and characterization of mesenchymal stem cells from human dental pulp and follicle. Int. J. Morphol., 31(2):739-746, 2013.

SUMMARY: It was recently discovered that dental tissues are important sources of mesenchymal stem cells (MSCs). In the oral cavity MSCs can be found in the pulp, dental follicle, apical papilla and gingival tissue, among others. Many studies support the therapeutic potential of MSCs in regenerative therapies. The objective of this study was to isolate and culture mesenchymal stem cells from human dental pulp and follicle, and to characterize their immunophenotype and differentiation potential to adipogenic, chondrogenic and osteogenic lineages. Oral cavity stem cells were cultured from pulp and dental follicle of wisdom teeth from young permanent teeth. Immunotypification of MSCs was performed by flow cytometry and cultures were evaluated for their ability to differentiate into the three lineages mentioned. Our results corroborate that cultured oral MSC cells isolated from pulp and dental follicle were mesenchymal in origin, being the latter more easy to obtain. Dental follicle MSCs have greater growth potential and differentiation capacity compared to dental pulp MSCs, probably due to their more immature developmental state.

KEY WORDS: Mesenchymal stem cells; Dental pulp; Follicle; Multilineage differentiation; Proliferation potential.

\section{REFERENCIAS BIBLIOGRÁFICAS}

Angiero, F.; Rossi, C.; Ferri, A.; Seramondi, R.; Magistro, S.; Farronato, D.; Benedicenti, S.; Farronato, G.; Fini, M.; Carpi, A. \& Cattoretti,
G. Stromal phenotype of dental follicle stem cells. Front. Biosci., 1-4:1009-14, 2012. 
Bansal, R. Regenerative endodontics: A state of the art. Indian J. Dent Res., 22(1):122-31, 2011

Buurma, B.; Gu, K. \& Rutherford, R. B. Transplantation of human pulpal and gingival fibroblasts attached to synthetic scaffolds. Eur. J. Oral Sci., 107(4):282-9, 1999.

Casagrande, L.; Cordeiro, M. M.; Nör, S. A. \& Nöor, J. E. Dental pulp stem cells in regenerative dentistry. Odontology, 99(1):1-7, 2011.

Chen, F. M.; Sun, H. H.; Lu, H. \& Yu, Q. Stem cell-delivery therapeutics for periodontal tissue regeneration. Biomaterials, 33(27):6320-44, 2012.

D'Aquino, R. Human neural crest-derived postnatal cells exhibit remarkable embryonic attributes either in vitro or in vivo. Eur. Cell Mater., 21:304-16, 2011.

Dominici, M.; Le Blanc, K.; Mueller, I.; Slaper-Cortenbach, I.; Marini, F.; Krause, D. et al. Minimal criteria for defining multipotent mesenchymal stromal cells. The International Society for Cellular Therapy Position Statement. Cytotherapy, 8(4):315-7, 2006.

Flores, E.; Montesinos, J. \& Mayani, H. Células troncales mesenquimales: historia, biología y aplicación clínica. Rev. Invest. Clín., 58(5):498$511,2006$.

Friedlander, L.; Cullinan, M. \& Love, R. Dental stem cells and their potential role in apexogenesis and apexification. Int. Endod. J., 42(11):955-62, 2009.

Friedenstein, A. J.; Chailakhyan, R. K. \& Gerasimov, U. V. Bone Marrow osteogenic stem cells: in vitro cultivation and transplantation in diffusion chambers. Cell Tissue Kinet., 20(3):263-72, 1987.

Guo, W.; Chen, L.; Gong, K.; Ding, B.; Duan, Y. \& Jin, Y. Heterogeneous Dental Follicle Cells and the Regeneration of Complex Periodontal Tissues. Tissue Eng. Part A., 18(5-6):459-70, 2012.

Honda, M.; Imaizumi, M.; Tsuchiya, S. \& Morsczeck, C. Dental follicle stem cells and tissue engineering. J. Oral Sci., 52(4):541-52, 2010.

Howard, D.; Buttery, L.; Shakesheff, K. \& Roberts, S. Tissue engineering: strategies, stem cells and scaffolds. J. Anat., 213(1):66-72, 2008.

Huang, G. T.; Sonoyama, W.; Liu, Y.; Liu, H.; Wang, S. \& Shi, S. The hidden treasure in apical papilla: the potential role in pulp/dentin regeneration and bioroot engineering. J. Endod., 34(6):645-51, 2008.

Huang, G. T. J. A paradigm shift in endodontic management of immature teeth: Conservation of stem cells for regeneration. J. Dent., 36(6):379-86, 2008.

Kenneth, G. The present and the future of stem cell therapies. FASEB J., 26:335-4, 2012.

Mitrano, T.; Grob, M.; Carrión, F.; Nova-Lamperti, E.; Luz, P.; Fierro, F.; et al. Culture and characterization of mesenchymal stem cells from human gingival tissue. J. Periodontol., 81(6):917-25, 2010.

Mitsiadis, T.; Feki, A.; Papaccio, G. \& Catón, J. Dental pulp stem cells, niches, and notch signaling in tooth injury. Adv. Dent. Res., 23(3):275-9, 2011.
Murray, P.; Smith, A.; Garcia-Godoy, F. \& Lumley P. Comparison of operative procedure variables on pulpal viability in an ex vivo model. Int. Endod. J., 41(5):389-400, 2008.

Petrovic, V. \& Stefanovic, V. Dental tissue-new source for stem cells. ScientificWorld J., 9:1167-77, 2009.

Rodríguez-Lozano, F.; Bueno, C.; Insausti, C.; Meseguer, L.; Ramírez, M.; Blanquer, M.; et al. Mesenchymal stem cells derived from dental tissues. Int. Endod. J., 44(9):800-6, 2011.

Saber, S. Tissue engineering in endodontics. J. Oral Sci., 51(4):495-507, 2009.

Salinas, C. \& Anseth, K. Mesenchymal stem cells for craniofacial tissue regeneration: designing hydrogel delivery vehicles. J. Dent. Res., 88(8):681-92, 2009.

Smith, A. J.; Cassidy, N.; Perry, H.; Bègue-Kirn, C.; Ruch, J. V. \& Lesot, H. Reactionary dentinogenesis. Int. J. Dev. Biol., 39(1):273-80, 1995.

Sunil, P. M.; Manikandhan, R.; Muthu, M. S. \& Abraham, S. Stem cell Stem cell therapy in oral and maxillofacial region: An overview. $J$. Oral Maxillofac. Pathol., 16(1):58-63. 2012.

Suzuki, T.; Lee, C.; Chen, M.; Zhao, W.; Fu, Qi J.; et al. Induced Migration of Dental Pulp Stem Cells for in vivo Pulp Regeneration. J. Dent. Res., 90:1013-8, 2011.

Tokalov, S.; Grüner, S.; Schindler, S.; Iagunov, A.; Baumann, M. \& Abolmaali, N. A number of bone marrow mesenchymal stem cells but neither phenotype nor differentiation capacities changes with age of rats. Mol. Cells, 24(2):255-60, 2007.

Thomson, A. \& Kahler, B. Regenerative endodontics - biologically-based treatment for immature permanent teeth: a case report and review of the literature. Aust. Dent J., 55(4):446-52, 2010.

Yao, S.; Pan, F.; Prpic, V. \& Wise, G. E. Differentiation of Stem Cells in the dental follicle. J. Dent. Res., 87(8):767-71, 2008.

Yen, A. \& Yelick, P. Dental Tissue Regeneration - A Mini-Review. Gerontol., 57(1):85-94, 2011.

Zhang, Q.; Shi, S.; Liu, Y.; Uyanne, J.; Shi, Y.; Shi, S.; et al. Mesenchymal stem cells derived from human gingiva are capable of immunomodulatory functions and ameliorate inflammation-related tissue destruction in experimental colitis. J. Immunol., 183(12):778798, 2009.

\section{Dirección para correspondencia: \\ Carolina Inostroza \\ Centro de Investigación en Biología \\ y Regeneración Oral (CIBRO), \\ Facultad de Odontología \\ Universidad de los Andes \\ Santiago \\ CHILE}

Recibido : 01-10-2012

Aceptado: 21-12-2012 